\title{
Protective effects of growth hormone on bacterial translocation and intestinal damage in rats with partial intestinal obstruction
}

\author{
Kaymakci A ${ }^{1}$, Guven $\mathrm{S}^{2}$, Ciftci I ${ }^{3}$, Akillioglu I ${ }^{4}$, Aktan $\mathrm{M}^{5}$, Eker $\mathrm{HH}^{6}$, Sutcu A ${ }^{7}$, Abasiyanik ${ }^{8}$ \\ Medeniyet University Goztepe Training and Research Hospital, Department of Pediatric Surgery, \\ Istanbul, Turkey. driciftci@yahoo.com
}

\begin{abstract}
Objective: One of the reasons of bacterial translocation (BT) is the complete or partial intestinal obstructions (PIO) of the gastrointestinal system. In this study, we aimed to investigate the effects of recombinant human Growth Hormone (rhGH) on BT in rats with partial intestinal obstruction (PIO).

Material and methods: The rats were randomly divided into the 4 groups: Group I: Sham-operated (SO) $(n=$ 12), Group II control PIO ( $n=12)$, Group III: PIO with rhGH treatment for 5 days $(n=12)$, Group IV: PIO with rhGH treatment 5 days before PIO and 5 days after PIO (a total of 10 days) $(n=12)$. In the groups III and IV, the effects of 5 and 10 days administered rhGH were examined.

Results: The level of serum and of intestinal fluid IgA was significantly higher in the Group IV compared to the Group I, Group II and Group III. In the Group IV, the number of small intestinal goblet and colonic goblet cells, and the lengths of intestinal mucosal villi and crypt depths were statistically significantly higher than in Groups II and III. The rate of bacterial translocation was higher in the Group II: $100 \%$ in MLNs, $41.6 \%$ in blood culture and $50.8 \%$ in the liver cultures, it was significantly higher compared to the other groups $(p<0.01)$.

Conclusions: The study results demonstrated that administration of rhGH to the rats with PIO for at least 10 days decreased bacterial translocation (Fig. 3, Ref. 25). Text in PDF www.elis.sk.

Key words: bacterial translocation; partial intestinal obstruction; rat; recombinant human Growth Hormone; mesenteric lymph ganglion.
\end{abstract}

The gastrointestinal system (GIS) as well as its functions of motility, absorption and secretion, has also immunologic, metabolic, endocrine functions and provides a mucosal defense barrier against translocation of bacteria/toxins from gut lumen into circulation and extra intestinal tissues (1). Bacterial translocation (BT) is defined as the passage of viable bacteria from the gastrointestinal tract through the epithelial mucosa. Intestinal bacterial overgrowth, intestinal hypomotility and increased mucosal permeability, immunodeficiencies are mechanisms suggested to increase BT $(2,3)$.

Partial intestinal obstructions (PIO) induce intestinal bacterial overgrowth and subsequently promote translocation (4). In the complete and PIO, microorganisms remain in close and longterm contact with the mucosa because of an impaired peristalsis and decreased amount of mucus. In these patients, the number of endogenous microorganisms increases besides intra-luminal stasis

${ }^{1}$ Medeniyet University Goztepe Training and Research Hospital, Department of Pediatric Surgery, Istanbul, Turkey, ${ }^{2}$ Umraniye Education and Research Hospital, Department of Pediatrics, Istanbul, ${ }^{3}$ Selcuk University, Medical Faculty, Department of Pediatric Surgery, Konya, Turkey, ${ }^{4}$ Baskent University, Konya Hospital, Department of Pediatric Surgery, Konya, Turkey, ${ }^{5}$ Necmettin Erbakan University, Medical Faculty, Depatment of Histology/Embriology, Konya, Turkey, ${ }^{6}$ Medical College of Gumushane University, Public health specialist, Gumushane, Turkey, ${ }^{7}$ Selcuk University, Medical Faculty, Department of Microbiology, Konya, Turkey, and ${ }^{8}$ Necmettin Erbakan University, Medical Faculty, Department of Pediatric Surgery, Konya, Turkey

Address for correspondence: I. Ciftci, MD, Selcuk Universitesi Tip Fakultesi, Cocuk Cerrahisi A.D. Konya, Turkey.

Phone: +903322415000, Fax: +903322412184 and the fluid accumulation $(5,6)$. Catabolic events and gastrointestinal dysfunction leads to the passage of the bacteria first in mesenteric lymph ganglions (MLGs) and then to other tissues and organs by increasing the mucosal permeability $(12,2)$.

Various trophic factors are tried and found effective in order to protect the integrity of GIS mucosa, at the same time, pointed that they decreased BT as well (2, 7-10). Although protective effects of GH have been reported in various studies of impairment of the gastrointestinal mucosa, including stress, sepsis, ischemia and subsequent reperfusion, the precise mechanisms of GI protection of GH are still unclear (11-15).

The aim of the present study was to evaluate the effects of subcutaneously administered GH on bacterial translocation (BT) in rats with partial intestinal obstruction.

\section{Material and method}

The study was conducted in the Experimental Laboratory at Selcuk University, Medical Faculty. All procedures were performed according to the Guide for the Care and Use of Laboratory Animals. All protocols were approved by the Institutional Animal Care and Use Committee of the University and followed the institutional guidelines for the care and use of laboratory animals. Experiments were performed on 48 Wistar Albino adult male rats weighted 250-300 grams. The animals were housed in wire mesh cages, at normal room temperature, and a 12-hour light/dark. The animals were fasted for 8 hours before and during experiment, and received serum physiologic $(\mathrm{SF})$ of $100 \mathrm{ml} / \mathrm{kg}$ /day via subcutane- 
ous route in the morning and evening for replacement. The rats were randomly divided into the 4 groups: Group I: Sham-operated (SO) $(n=12)$, Group II control PIO ( $\mathrm{n}=12)$, Group III: PIO with rhGH treatment for 5 days $(\mathrm{n}=12)$, Group IV: PIO with rhGH treatment 5 days before PIO and 5 days after PIO (a total of 10 days) $(\mathrm{n}=12)$. In the groups III and IV, the effects of 5 and 10 days administered rhGH were examined.

\section{Surgical procedures}

All procedures were performed under ether anesthesia applied $30 \mathrm{~min}$ prior to the experiment. The middle laparotomy was performed under sterile conditions. PIO was made with placement of a $8 \mathrm{~F}$ nutrition catheter $5 \mathrm{~cm}$ proximal of ileocecal valve to the anti-mesenteric edge of the bowel and ligation together with the bowel, using a $4 / 0$ atraumatic silk. After the removal of the catheter, the passage from the proximal of the stenosis area to the distal bowel was controlled. In the Sham group, 5 minutes after the formation of partial intestinal obstruction, both catheter and silk were removed.

The rats in the group III received $\mathrm{rhGH}(16 \mathrm{IU} / \mathrm{ml}$ of Genotropin, $3 \mathrm{IU} / \mathrm{mg}$ of specific activity, $1 \mathrm{ml}$ of Kabi Pharmacia, $16 \mathrm{IU}$ of Recombinant somatotropin, $2.0 \mathrm{mg}$ of aminoacetic acid, $41 \mathrm{mg}$ mannitol, $0.29 \mathrm{mg}$ of sodium dihydrogen phosphate, $0.28 \mathrm{mg}$ of disodium phosphate, $3.0 \mathrm{mg}$ of m-cresol, $1 \mathrm{ml}$. of water for injection, $1.15 \mathrm{ml}$ of the volume of the solution) between $08.00 \mathrm{AM}$ and $08.00 \mathrm{PM}$ at a dose of $1.0 \mathrm{mg} / \mathrm{kg} /$ day subcutaneously for 5 days, immediately after the operation. In the group IV, rhGH started 5 days before PIO and continued 5 days after ligation at the same dose (a total of 10 days). All groups underwent reoperation on the $5^{\text {th }}$ day after PIO. Blood, intestinal fluid, hepatic and mesentery lymph ganglions samples were obtained for biochemical, immunological, microbiological and histopathological analysis. Hepatic tissue and MLGs were squeezed and cultured. Culture was performed on eosin-methylene-blue (EMB), bloody medium and Saboroud-dextrose medium. Serum and intestinal fluid IgA were measured using radial immunodiffusion method.

\section{Histological examination of intestinal mucosa}

Small intestinal specimens were taken $5 \mathrm{~cm}$ proximal from ligation and from ascending colon. Small and large intestinal specimens (6 samples per animal) were fixed in formaldehyde, dehydrated with alcohol and embedded in paraffin, then cut in $5 \mu \mathrm{m}$ sections and stained with hematoxylin eosin and Periodic acid-Schiff reaction (PAS). The specimens were assessed under a light microscope by the same experienced pathologist. Length and depth calculations of the intestinal villous and crypts were performed with an eyepiece micrometer under the light microscope (BH-2 Olympus), micrometer calibration was done for 40 magnitude objective. The calculation of Goblet cells were done on PAS stained slides by counting the total number of purple stained cells which easily can be distinguished from other enterocytes lined on villous and crypts. For evaluation of length, depth's and goblet number, measurements were done as repeating every sample for six distinct times, then taking the arithmetic mean of this six for student's-T test statistical analysis. To make more open this "six" returns; for each animal $(n=12 \times 4=48)$ six slide was prepared (total 288 slides) and for each slide six separated microscopic fields (1728) was calculated. All photomicrographs were taken under the light microscope with image analysis software equipment attached (Olympus Application Software DP-2BSW)

\section{Statistical analysis}

When evaluating the results of the study, NCSS (Number Cruncher Statistical System) 2007\&PASS 2008 Statistical Software (Utah, USA) was used for the statistical analysis. KruskalWallis test was used to compare the quantitative data between the groups and the Mann Whitney U test was used to determine the group that led to the difference. For the comparison of the parameter within the group, Wilcoxon sign test was used. The Pearson Chi-Square test was used for the comparison of qualitative data. The significance level was considered as $\mathrm{p}<0.05$.

\section{Results}

\section{Intraoperative results}

In the relaparotomy of the rats of PIO group, it was observed that the small intestine at the proximal of the ligation was largely dilated, there was intra-luminal fluid sequestration and edemous wall, and there were no bleeding and necrosis. The ligation did not completely close the intestinal lumen and the diameter of the colon was normal.

\section{Serological results}

A statistically significant difference was found between the groups in terms of the levels of serum IgA. The levels of serum IgA were significantly higher in the Group IV compared to the Group I, Group II and Group III ( $p<0.05, p<0.01)$. The levels of serum IgA were significantly lower in the Group II than in Groups I and III $(p<0.01)$. No statistically significant difference was found between the levels of serum IgA in the Group I and Group III ( $p>$ 0.05 ) (Fig. 1). The IgA levels of intestinal fluid were significantly higher in the Group IV than in Group I, II and III ( $p<0.01)$. The

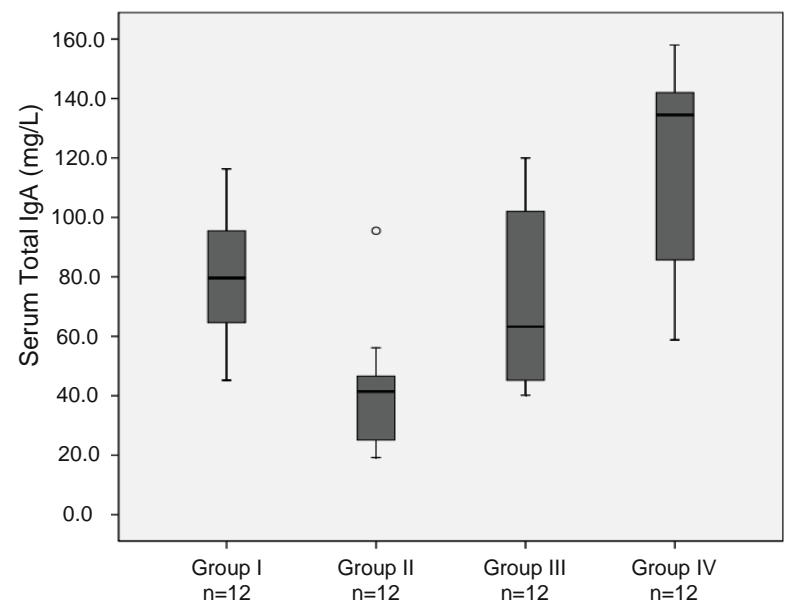

Fig. 1. The distribution of the serum IgA levels in each group. 


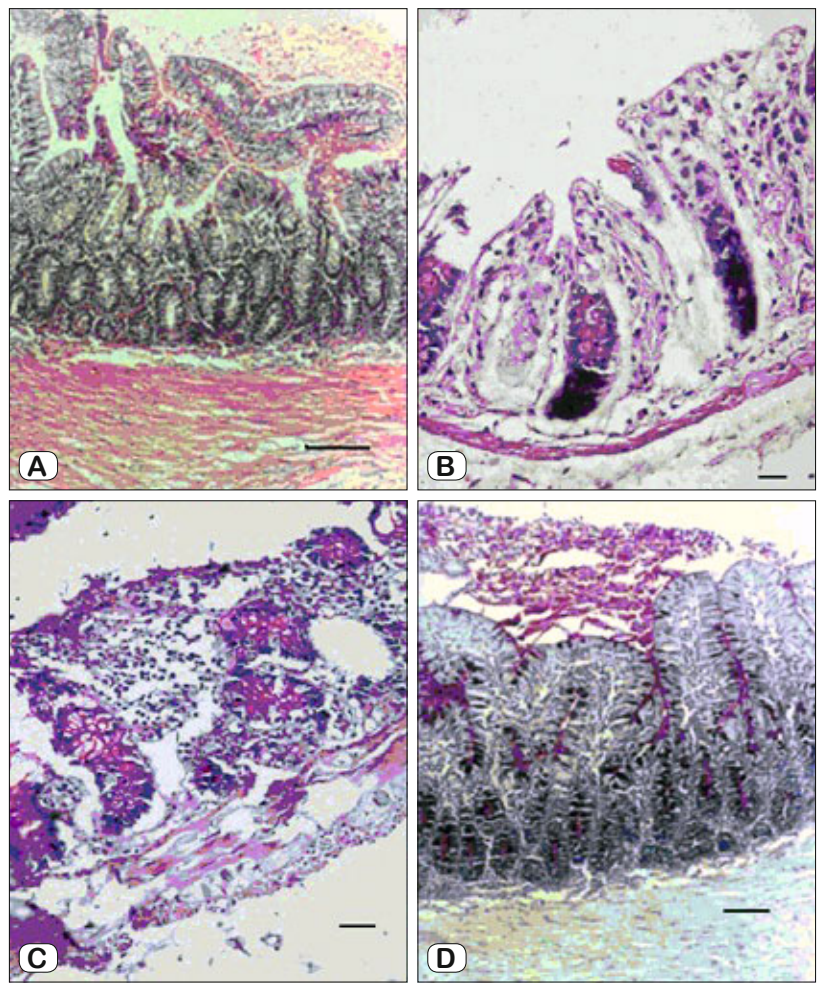

Fig. 2. The histopathological findings from small intestine in each group. A) The figure shows the histopathological findings obtained from small intestine in the Group I (hematoxylin-eosin, x100). The length of intestinal mucosal villi and the number of goblet cells are in normal range (Bar indicates 150 micron). B) The histopathological findings obtained from small intestine of the Group II showed short length of villus, reduced number of goblet cells and released of goblet cells secretions into the lumen (Bar indicates 50 micron) (PAS, x200). C) The histopathological findings from small intestine of the Group III showed atrophy of the small intestine, deformation of the crypts, erosion of the surface epithelial layer, decreased number of goblet cells (Bar indicates 50 micron) (PAS, x200). D) The histopathological findings of the Group IV (PAS, x100): small intestinal villus lengths and the number of goblet cells are close to normal, lumen is reach of mucus secretions (Bar indicates 100 micron).

IgA levels of intestinal fluid were not statistically different between other groups $(\mathrm{p}>0.05)$. In the Group II, III and IV the IgA levels obtained from the intestinal fluid were significantly higher than serum IgA levels $(\mathrm{p}<0.01, \mathrm{p}<0.05)$.

\section{Histopathological results}

In the Sham group, the histopathological findings obtained from small intestine (Fig. 2A) and colon were normal, the intestinal villus lengths and the numbers of small intestinal and colonic goblet cells were greater than in other groups $(p<0.01)$. In the Group II, it was observed that the villus length in the small intestine was statistically shorter than in the Groups I, III and IV $(\mathrm{p}<$ 0.01 ) (Fig. 2B). In addition, it was found that the crypt depths of colon were normal. It was seen that the goblet cells in the group III (Fig. 2C) were empty and their secretions were released into the lumen. The short length of the villi and the reduced number of goblet cells were statistically significant only in the rats of the

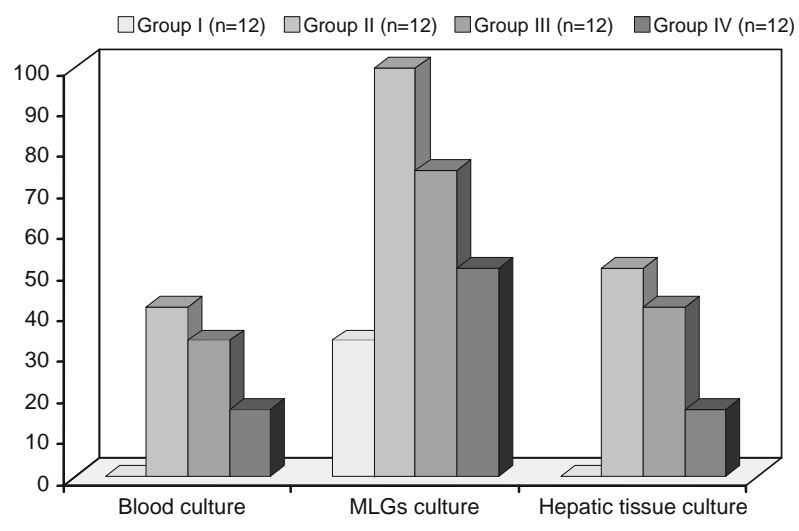

Fig. 3. The growth in blood culture, MLGs and hepatic tissue culture in each group.

Group II ( $p<0.01)$. In the group IV (Fig. 2D), an increased number of emptied small intestinal goblet cells and lymphocyte cell infiltration in small intestine and colon was observed. In this group, the number of intestinal and colonic goblet cells and the villus length and crypt depths were statistically significantly higher compared to the Groups II and III $(\mathrm{p}<0.001)$.

\section{Microbiological results}

In the first group, $3 / 12$ rats (33.3\%) showed growth in MLGs and did not show growth in the blood and hepatic cultures. In the second group, $100 \%$ of the rats showed growth in MLGs, 5/12 rats $(41.6 \%)$ showed growth in the blood culture and 7/12 (50.8 $\%)$ showed growth in the hepatic cultures. In the third group, 9/12 rats (75\%) showed growth in MLGs, 4/12 (33.3\%) showed growth in blood cultures and 5/12 (41.6\%) showed growth in hepatic cultures. In the fourth group, $7 / 12$ rats $(50.8 \%)$ showed growth in MLGs, $2 / 12$ (16.6 \%) showed growth in blood culture and $2 / 12(16.6 \%)$ showed growth in hepatic culture. In the blood cultures, no statistically significant difference was found between the groups in terms of growth $(p>0.05)$. The growth observed in MLGs and hepatic cultures of the rats in the Group II was significantly higher compared to other groups $(\mathrm{p}<0.01, \mathrm{p}<0.05)$ (Fig. 3). In all groups, aerobic bacteria were more commonly isolated: E. coli (12, $48 \%$ ), Proteus (5, $76 \%$ ), Enteroccocus (2, 88 $\%)$. Anaerobic pathogens as Peptostreptococcus (3, $83 \%)$ were rarely isolated (Fig. 3).

\section{Discussion}

Pathologic conditions such as necrotizing enterocolitis, sepsis, stress, burns, obstructive jaundice, and trauma compromised the integrity of the intestinal mucosal barrier $(1,2,5,7,8,13,14$, 16). Intestinal mucosa plays an important role in the prevention of BT. The partial obstruction impairs intestinal motility, absorption and secretion and leads to delay in the bacterial elimination, which induces intestinal bacterial overgrowth and promotes BT. $\mathrm{BT}$ is suspected as an important reason in the pathogenesis of the sepsis and multi organ failure (3-6). In a study conducted on the 
rats, a BT was seen at $60 \%$ in the first 6 hours in the rats underwent proximal complete ligation of small intestine and at $40 \%$ in the MLG in the rats with distal ligation of small intestine. In the same study, after 24-48 hours, BT was not only limited to MLGs but spread to the liver, spleen, and blood stream. The isolation of intestinal bacteria in normally sterile, MLGs is considered as a direct evidence of BT. Moreover, after 48 hours, a destruction of the villus structures and epithelial cells were observed (4).

In our study, on 5th day after PIO the bacterial growth in MLGs, liver and blood cultures in the Group II was $100 \%, 50.8 \%$, $41.6 \%$ respectively. No significant difference between the groups was found in terms of the growth observed in blood cultures. Histopathological examination of small intestine in the Group II rats demonstrated a destruction/shortening of the villus heights and decrease of small intestinal goblet cell numbers. The similar results were reported in human studies (6). The large presence of bacterial translocation in MLG and other tissues is attributed to the fasting and to the long-term partial obstruction. In the fasting state, mucosal permeability for macromolecules increases and the atrophy of intestinal mucosa, a shortening of villus height and a decrease in the growth of epithelial cells and the activity of intestinal enzyme occurred (10). In our Sham group, the BT of $33.3 \%$ in MLG might be attributed to the fasting state. It was found that trophic factors such as IGF-1, rhGH, glutamine, IgA were effective in the protection of the intestinal functions and structure as well as the prevention of BT $(13,17,20,23)$. GH enhances Th1 cytokine activity, stimulates immunoglobulin secretion of B cells, NK cell activity, phagocytosis, and killing capacity of neutrophils and macrophages $(18,20,21)$. Prieto et al (23) demonstrated that rhGH could promote the release and chemotaxis of neutrophils, minimize the spread of bacteria and attenuate bacteria/endotoxin translocation, and then reduce plasma endotoxin level.

Experimental studies showed that, during conditions such as intestinal obstruction, obstructive jaundice, burning, trauma, fasting and chemotherapy, serum IgA levels were reduced, the mucosal resistance was decreased and BT occurred $(12-17,20)$. The main immunoglobulin on mucosal surfaces is $\operatorname{Ig} \mathrm{A}$. $\operatorname{Ig} \mathrm{A} 2$ accounts for $15-20 \%$ of the total IgA and it is more abundant in the secretions. IgA neutralizes the bacteria by adhesion. This occurs in the mucus. The complex of "mucus-IgA-bacteria" is eliminated with peristaltic movements of the bowel. In the rabbits, it was shown that intestinal IgA had a protective effect in the neonatal bowelderived sepsis (22). Secretory IgA on intestinal mucosal surfaces inhibits bacterial adherence to mucosal surfaces and appears to be more effective in reducing the spread of bacteria penetrated intestinal mucosa than inhibiting the initial translocation of bacteria across the intestinal mucosa to the MLGs. A number of studies revealed that $\mathrm{GH}$ had important role in regulation of humoral and cellular immune functions $(9,17,22-25)$. The administration of rhGH increases the level of total serum and intestinal fluid IgA and thereby, the bacterial growth may be inhibited and bacterial translocation may be reduced. In our study, it was demonstrated that administration of rhGH increased the total level of IgA in serum and in the intestinal fluid, and that it provided a better prevention of bacterial translocation depending on the time.
Recent studies demonstrated that rhGH might protect the damage of the intestinal mucosa by inhibiting apoptosis of intestinal mucosa cells and increasing of IGF-1 levels $(11,15,17,25)$. The biological effects of GH are indirectly mediated by IGF-1. IGF-1 can prevent intestinal atrophy in septic rats and protect the integrity of intestinal structure $(11,12,13,18,21)$. Gary et al reported that the development of bacterial translocation is inversely correlated with serum IGF-1 levels and treatment with IGF-1 decreased enterocyte apoptosis (19). Thus, GH improves the impairment of the intestinal mucosa and maintains the structure and function of the intestinal mucosal barrier $(12-14,20)$.

Studies have demonstrated increased villus height and crypt depth, when rats were given rhGH alone or in combination with glutamine $(10,13,15,17,23)$. In agreement with these studies, we determined a significant increase of the villus height and the numbers of small intestinal and colonic goblet cell after 10 days of rhGH ( $1 \mathrm{mg} / \mathrm{kg} /$ day) administration, also increased levels of serum and intestinal fluid IgA were observed. However, it was observed that an administration of rhGH during 10 days led to a decrease by $50 \%$ in the BT seen in MLGs. In the cultures, the most abundantly growing bacteria were E. coli. As E. coli is present in the bowel, it is thought that it leads to BT more than other microorganisms.

Consequently, the administration of rhGH to the rats for at least 10 days decreases intestinal damage and subsequent BT, with its protective effects in maintaining the integrity of intestinal mucosa and the levels of IgA. It was thought that these effects might be mediated by IGF-1 and rhGH receptors located in the intestine. rhGH could accelerate the clearance of bacteria, minimize the spread of bacteria to blood and decrease plasma endotoxin and proinflammatory cytokines levels. We suggested that it would be very useful to perform studies for investigation of rhGH effects on BT in humans.

\section{References}

1. Stechmiller JK, TreloarD, Allen N. Gut dysfunction in critically ill patients: a review of the literature. Am J Crit Care 1997; 6: 204-209.

2. Berg R. Bacterial translocation from the gastrointestinal tract. Trends Microbiol 1995; 3: 149-154.

3. Berg R. The indigenous gastrointestinal microflora. Trends Microbiol 1996; 4: 430-435.

4. Deitch EA, Bridges WM, Ma JW, Ma L, Berg RD, Specian RD. Obstructed intestine as a Reservoir for Systemic Infection. Am J Surg 1990; 159: 394-401.

5. Sagar PM, MacFie J, Sedman P, May J, Mancey-Jones B, Johnstone D. Intestinal obstruction promotes gut translocation of bacteria. Dis Colon Rectum 1995; 38: 640-644.

6. O’Boyle CJ, MacFie J, Mitchell CJ, Johnstone D, Sagar PM, Sedman PC. Microbiology of bacterial translocation in humans. Gut 1998; 42: 29-35.

7. Ding LA, Li JS, Li YS, Liu FN, Tan L. Prophylactic treatment with growth hormone improves intestinal barrier function and alleviates bacterial translocation in stressed rats. Chin Med J 2004; 117: 264-269. 
8. Jeschke MG, Herndon DN, Finnerty CC, Bolder U, Thompson JC, Mueller $\mathbf{U}$ et al. The effect of growth hormone on gut mucosal homeostasis and cellular mediators after severe trauma. J Surg Res 2005; 127: 183-189.

9. Ersoy B, Ozbilgin K, Kasirga E, Inan S, Coskun S, Tuglu I. Effect of growth hormone on small intestinal homeostasis relation to cellular mediators IGF-I and IGFBP-3. World J Gastroenterol 2009; 21; 15: 5418-5424.

10. Wischmeyer PE. Glutamine: role in gut protection in critical illness. Curr Opin Clin Nutr Metam Care 2006; 9: 607-612.

11. Huang Y, Wang SR, Yi C, Ying MY, Lin Y, Zhi MH. Effects of recombinant human growth hormone on rat septic shock with intraabdominal infection by E. coli. World J Gastroenterol 2002; 8: 1134-1137.

12. Mylonas PG, Matsouka PT, Papandoniou EV, Vagianos C, Kalfarentzos F, Alexandrides TK. Growth hormone and insulin-like growth factor I protect intestinal cells from radiation induced apoptosis. Mol Cell Endocrinol 2000; 160: 115-122.

13. Celebi F, Ozturk G, Kizilkaya M. The effects of combined use of glutamine and growth hormone on the bacterial translocation associated with obstructive jaundice. Saudi Med J 2008; 29: 989-993.

14. Huang KF, Chung DH, Herndon DN. Insulin like Growth Factor 1 (IGF-1) Reduces Gut Atrophy and Bacterial Translocation After Severe Bum injury. Arch Surg 1993; 128: 47-54.

15. Jung SE, Youn YK, Lim YS, Song HG, Rhee JE, Suh GJ. Combined Administration of Glutamine and Growth Hormone Synergistically Reduces Bacterial Translocation in Sepsis. J Korean Med Sci 2003; 18: 17-22.

16. Ciftci I, Ozdemir M, Aktan M, Aslan K. Bacterial translocation and intestinal injury in experimental necrotizing enterocolitis model. Bratisl Lek Listy 2012; 113(4): 206-210.

17. Yi C, Cao Y, Wang SR et al. Beneficial effect of recombinant human growth hormone on the intestinal mucosa barrier of septic rats. Braz J Med Biol Res 2007; 40: 41-48.
18. Chen K, Okuma T, Okamura $\mathbf{K}$ et al. Insulin-like growth factorI prevents gut atrophy and maintains intestinal integrity in septic rats. J Parenter Enteral Nutr 1995; 19: 119-124.

19. Hunninghake GW, Doerschug KC, Nymon AB et al. Insulin-like Growth Factor-1 Levels Contribute to the Development of Bacterial Translocation in Sepsis. Am J Respir Crit Care Med 2010; 182: 517-525.

20. Scopa CD, Koureleas S, Tsamandas AC et al. Benefical effects of growth hormone and ILGF I on intestinal bacterial translovation, endotoxemia, and apoptosis in experimental jaundiced rats. J Am Coll Surg 2000; 190: 423-431.

21. Bortvedt SF, Lund PK. Insulin-like growth factor 1: common mediator of multiple enterotrophic hormones and growth factors. Curr Opin Gastroenterol 2012; 28: 89-98.

22. Maxson RT, Jackson RJ, Smith SD. The Protective Role of Enteral IgA Supplementation in Neonatal Gut Origin Sepsis. J Pediatr Surg 1995; 30: 231-234.

23. Guo G, Bai X, Cai C et al. The protective effect of different enteral nutrition combined with growth hormone on intestinal mucosal damage of scalded rats. Burns 2010; 36: 1283-1288.

24. Prieto I, Gomez de Segura IA et al. Growth hormone reduces bacterial translocation in radiation enteritis in the rat. Rev Esp Enferm Dig 1998; 90: 353-360.

25. Lorenzo-Zúniga V, Rodríguez-Ortigosa CM, Bartolí R, MartínezChantar ML, Martínez-Peralta L, Pardo A et al. Insulin-like growth factor I improves intestinal barrier function in cirrhotic rats. Gut 2006; 55: 1306-1312. 